\title{
Micro-organisms and cultivated edible fungi
}

\author{
MILOSLAV STANĚK
}

STANËK, M. 1978: Micro-organisms and cultivated edible fungi. - Karstenia 18 (suppl.).

Research on the changes in the populations of micro-organisms and the function of the individual species and groups in the mushroom compost during fermentation have been reviewd. The role of bacteria assoclated with mushroom mycelium and functioning in the hyphosphere, effect of micro-organisms on fruit-body formation and interactions between micro-organisms and Agaricus bitorquis have been discussed.

M. Stanek, Institute of Microbiology, Czechoslovak Academy of Sciences, Budejovick 1083 , 14200 Prague 4, Czechoslovakia.

The role of micro-organisms in the growing of edible higher fungi is very important. It is evident that in commercial cultivation mostly mixed cultures of higher fungi as well as specific micro-organisms are applied, which often form associations of mutually influencing partners.

Micro-organisms and mushrooms (Agarious bisporus, A. bitorquis)

Especially important are micro-organisms in the culture of the mushroom Agaricus bisporus (Lange) Singer.They

- form during the composting of horse manure a suitable medium for the mushroom,

- influence the growth of the mushroom mycelium, accompanying it in the compost,

- provoke the formation of mushroom fruit-bodies when colonizing the casing layer.

Micro-organisms inhabiting mushroom compost during fermentation

Micro-organisms colonizing the mushroom compost during fermentation, i.e. during composting of horse manure or other organic raw materials on piles, and during so-called pasteurization can be regarded as active factors in the preparation of the mushroom nutrient medium. They change the chemical composition of the compost and its physical properties, and make the growth of competitive micro-organisms more difficult.

The first more detailed data on micro-organisms inhabiting the mushroom compost were published by Waksman et al. (1939). They had found that at temperature $50-65^{\circ} \mathrm{C}$ the compost was colonized mostly by thermophilic actinomycetes and bacteria, and at $50^{\circ}$ $\mathrm{C}$ by the thermotolerant fungi Monospora spp., Sepedonicum spp. Bels-Koning et al. (1962) and Fergus (1964) had drawn attention to the importance of the thermotolerant fungus Humicola spp. In recent years changes in the populations of micro-organisms and the function of the individual species and groups in the mushroom compost during fermentation have been studied more thoroughly. Although the methods applied by various authors were different, the results were consistent of the whole:

- Number of micro-organisms growing at $25^{\circ} \mathrm{C}$ decreases and number of thermotolerant and thermophilic micro -organisms increases. The dominant types of micro -organisms are as follows: mesophilic and thermotolerant sporulating bacteria and quickly growing thermotolerant fungi (Phycomyces-Mucor spp., etc.) at the start of the fermentation processes; thermophilic actinomycetes (streptomyces thermovutgaris, Thermomonospora spp. etc.) and non-sporulating bacteria (Pseudomonas spp.) during the maximal period of the fermentation process; and non-sporulating bacteria and thermotolerant fungi (Humicola spp.) at the end.

- Various groups of micro-organisms take part in the decomposition of various substances of plant origin and in the formation of new substances. Some thermophilic actinomyces and thermotolerant fungi decompose cellulose. Bacteria accompanying these micro-organisms do not decompose cellulose; however, the decomposition continues more quickly when they are present: They produce the polysaccharides which are 2-9 times better utilized by the mushroom mycelium than glucose alone (Staněk 1971, Eddy \& Jacobs 1976).

- Some thermophilic actinomycetes produce amino acids (Park 1971) which are utilized by the mushroom as a source of nitrogen; perhaps the microbial cell -proteins are utilized directly, too (Wood 1974, Eddy \& Jacobs 1976).

- Some strains of Streptomyces spp. and Humicola spp. form pantothenic acid, nicotinic acid, biotin, mesoinositol and thiamine (Staněk \& Žatecka 1967, Stanĕk 1971), the stimulating effect of which on 
the growth of mushroom mycelium has already been proved by Treschow (1942).

- Finally, the metabolic activity of numerous micro -organisms corresponds to the formation of an apparently selective medium in which the mushroom crops will develop. The assumption of the selectivity of the mushroom substrate is based on the formation of the bacterial polysaccharide - humine acids complex (Eddy \& Jacobs 1976), mostly formed by the activity of Humicola spp. (Gordienko \& Staněk 1977, unpublished data).

Bacteria assooiated with mushroom mycelium and functioning in the hyphosphere

The number of bacteria and fungi decreases during the period that the mushroom mycelium colonizes the compost. In the vicinity of mushroom hyphae gram -negative bacteria predominate whose properties are different from bacteria occurring in compost without mushroom mycelium. The majority of them grow poorly in nutrient solutions containing mineral nitrogenous substances and glucose as the source of carbon.

The growth of some strains $(38 \%)$ was stimulated by the filtrate of pure liquid mushroom culture.

Bacteria occurring on the surface of mushroom mycelium utilized preferentially glutamic acid, less arginine, alanine, cystine and aspartic acid. The culture fil-

trate of these bacteria stimulated growth of mushroom mycelium (in average by $37 \%$ ), Stanék 1976).

Micro-organisms occurring in the surrounding of mushroom hyphae were called "hyphosphere" micro -organisms and the area close to particular hyphae "hyphosphere" (the term "hyphosphere" was first used in 1953 by Thornton who described a similar phenomenon in the hyphae of the fungus Rhizoctonia solani). It is considered probable that the advantageous interaction between mushroom mycelium and hyphosphere micro-organisms enables a rapid colonization of compost with mushroom mycelium.

It seems that during the colonization of the compost (during "spawn-run") the mushroom preferentially uses bacterial polysaccharides (Eddy \& Jacobs 1976) or lignoprotein and then - from the stage of initiation of fruit-bodies ("pinning") onwards - it uses cellulose (Gerrits 1969), too. The quantity and quality of the population of micro-organisms in the substrate change during the cropping, too (Stanek et al. 1976). The highest amounts of micro-organisms were ascertained in the substrate in the period of the highest mushroom yields. The function of these micro-organisms is as yet unknown.

\section{Effect of micro-organisms on fruit-body formation}

The casing layer is the site of a critical change in the development of the mushroom that occurs when the mycelium forms a primordium which then develops into a fruit-body. The investigation of Eger (1962) showed that micro-organisms took part in this change leading to primordium formation. Hayes et al. (1969) studied the activities of some strains of Pseudomonas putida which they found to be active in promoting the fruiting of $A$. bisporus in pure culture. Ferrous ion was found to stimulate fruiting and it was suggested that $P$. putida and other organisms stimulate fruiting by releasing ferrous ions (Hayes 1971). Couvy 1976 studied the fruiting of A. bisporus in sterile medium and Imbernon (1974) the microbiology of casing materials during growth and fruiting of the mushroom. It seems that the most important role belongs to the inhibitors - the volatile metabolites produced by the mushroom mycelium and inactivated in the presence of the micro-organisms.

Interactions between micro-organisms and Agaricus bitorquis

The same interactions take place between micro-organisms and $A$. bitorquis (Quél.) Sacc. as in the culture of A. bisporus. The only important difference is in the formation of fruit-bodies: the formation of primordia proceeds well without bacteria in the medium, too.

\section{Micro-organisms and other cultivated edible fung 1}

Grabbe (1977) divided the species of cultivated edible higher fungi into two groups: "primary destroying fungi":and "secondary destroying fungi". The first group comprises the species colonizing relatively micro-organism-free substrates, i.e. phytopathogenic and wood-destroying fungi: Pleurotus ostreatus and other species of Pleurotus, Kuehneromyces (Pholiota), mutabilis, Lentinus edodes, etc. These fungi are more responsive to microbial activity than those of the other group which comprise species (Stropharia rugoso-annulata, Volvariella volvacea, etc.) that colonize the substrate inhabited already before by micro-organisms, similarly as in the case of $A$. bisporus.

The original methods of cultivation of these "primary destroying fungi" utilized the nutrient substrates inhabited poorly by micro-organisms, mostly wood. The other methods aimed at cultivation on sterilized substrates. The investigations done in Hungary (Gyurkó 1971) and in Czechoslovakia (Staněk \& Ryšavá 1971) showed that the cultivation of these fungi was possible in materials fermented at $50-60^{\circ} \mathrm{C}$ for a few days only. It has been demonstrated that the short-term fermented substrates (wheat straw, maize cobs, etc.) were mostly colonized by spore-forming bacteria (Bacillus mesentericus, $B$. macerans). Some of these bacteria have produced antiobiotics and polysaccharides which inhibit the growth of competitive micro-organisms (Gyurkó 1974, Mrázková \& Staněk 1974).

In our experiments the mycelium of P.ostreatus grew better in substrates inoculated with selected strains of bacteria ( $B$. macerans) before the fermentation than in those not inoculated. After the inoculation of the substrate the yield in the culture of $P$. ostreatus was higher (Mrázková et al. 1977). 


\section{Conclusions. Practical application of results}

The understanding of the fact that the micro-organisms colonizing the nutrient substrates and mycelia of the higher fungi form a mixed culture enables the preparation of new methods of cultivation of various fungi. For instance, in the cultivation of the mushroom $A$. bisporus the problems of correctly performed fermentation "in bulk" (Edwards 1977, Vedder 1977) and the problems of improved control over the cropping (Flegg 1976) are much discussed at present. Knowledge of the microbiological processes in the fermented substrates and in the casing layer may help to solve these problems.

Many problems are open in the cultivation of other edible higher fungi. The cultivation in sterilized substrates (Till 1962) is very expensive. The conditions in non-sterilized substrates are variable and they may be modified be means of suitable fermentation towards better control over the cultivation of the fungus. Microbiological methods will be very helpful in this control.

\section{References}

Bels-Koning, H.C., Gerrits, J.P.G. \& Vaandrager, M.H. 1962: - Mushroom Sci. 5: 165-169.

Couvy, J. 1976: - Mushroom Sci. 9: 157-164.

Eddy, B.P. \& Jacobs, L. 1976: - Mushroom J. No. 36. -"- 1977: - Der Champignon 17 (187): 26-30.

Edwards, R.L. 1977: - Mushroom J. No. 52: 111-114.

Eger, G. 1962: - Mushroom Sci. 5: 314-320.

Fergus, C.L. 1964:- Mycologia 56: 267-284.

Flegg, P.B. 1976: - Mushroom J. No. 46: 330-333.
Gerrits, J.P.G. 1969: - Mushroom Sci. 7:111-126. Grabbe, K. 1977: - Der Champignon 17 (189): 24-80.

Gyurkó, P. 1971: - Mushroom Sci. 8: 461-470.

-" - 1974: - In: Physiology, Ecology and Cultivation of Edible Fungi, Int. Symp., ČssR, May 13-18 1974, pp. 20-21.

Hayes, W.A. 1969:-Mushroom Sci. 7: 173-185.

-"- 1971: - Mushroom Sci. 8: 663-674.

Hayes, W.A., Randle, P.E. \& Last, F.T. 1969: - Ann. Appl. Biol. 64: 177-187.

Imbernon, M. 1974: - 9th Congr. Mushroom Science, Tokyo (Summary of ref.).

Mrázková, L. \& Staněk, M. 1974: - In: Physiology, Ecology and Cultivation of Edible Fungi, Int. Symp., ČSSR, May 13-18 1974, pp. 18-19.

Mrázková, L., Zalábák, V. \& Staněk, M. 1977: - In: Industrial Growing of Edible Fungi, Konf., Praha, May 24-25 1977, pp. 119-121 (In Russ.).

Park, J.Y. 1971: - MGA Bull. (London) 254: 78-83.

Stanĕk, M. 1969: - Mushroom Sei. 7: 161-172.

-" 1971: - Mushroom Sci. 8: 798-811.

-"- 1976: - Mushroom Sci. 9: 198-207.

Staněk, M., Kubßtová, Z. \& Srp, A. 1976: - Vĕøtník pěstitelu 12: 112-114 (In Czech.).

Staněk, M., Žatecká, J. 1971: - Pěstování žampiónu 8: 59-60 (In Czech, Engl. summary).

Till, 0. 1962: - Mushroom Sci. 5: 127-134.

Thornton, R.H. 1953: - Research (London) 6: 6.

Treschow, C. 1943: - Naturwissenschaften 31: 210.

Vedder, P.J. C. 1976: - Mushroom J. No. 53: 152-158.

Waksmann, S.A., Umbreit, W.W. \& Cordon, T.C. 1939: - Soil Sci. 47: 37-60.

Wood, D.A. 1974: - Mushroom J. No. 22: 393-396. 